\title{
A inclusão digital do projeto UCA Total no município de São João da Ponta no estado do Pará.
}

\author{
Tânia Elizette Barata Pereira ${ }^{1}$, Alcides Fernando Gussi \\ ${ }^{1}$ Núcleo de Tecnologia Educacional de Belém - NTE Belém, PA - Brasil. \\ ${ }^{2}$ Universidade Federal do Ceará - Fortaleza, CE - Brasil. \\ taniabarataabs@gmail.com, agussi@uol.com.br
}

\begin{abstract}
This work had as its theme the implementation of the One Laptop per Child program - Total UCA in São João da Ponta of Pará, in order to analyze the socio digital inclusion provided to participants. To this end, we conducted an ethnographic research, in the perspective of a project description in SJP. In this sense, we take as guiding analytical category, the notion of social and digital inclusion. The results indicate that UCA project nears digital social inclusion approach; however, it was observed that the Institute did not change the physical structure of schools benefiting from the project, or impregnated in this space, but, in contrast, was potentially absorbed by the community where the headquarters of São João da Ponta perceive indications digital literacy and also the development of community's practices.
\end{abstract}

Resumo. Este trabalho teve por temática a implementação do programa Um Computador por Aluno - UCA Total no município de São João da Ponta no Pará, no sentido de analisar a inclusão sócio digital proporcionada aos participantes. Para tanto, realizamos uma pesquisa de cunho etnográfico, na perspectiva de realizar uma descrição do projeto em São João da Ponta. Neste sentido, tomamos como categoria analítica norteadora, a noção de inclusão sócio-digital. Os resultados indicam que o projeto UCA se aproxima da abordagem de inclusão sócio digital; contudo, foi observado que o UCA não modificou a estrutura física das escolas beneficiadas com o projeto, nem impregnou neste espaço, mas, em contrapartida, foi potencialmente absorvido pela comunidade da sede de São João da Ponta onde percebemos indícios de letramento digital e também o desenvolvimento de comunidades práticas.

\section{Introdução}

Nas ultimas décadas, algumas políticas educacionais se voltaram sobre a necessidade de se trazer para a escola as novas tecnologias digitais e diminuir a exclusão digital com o intuito, em última instância, de modificar as práticas escolares diante de novos papeis que a tecnologia assume na sociedade contemporânea.

Nesse contexto é que surgiu o projeto, hoje programa UCA, iniciado no ano 2007 “em sintonia com Plano de Desenvolvimento da Educação - PDE e com os propósitos do Programa Nacional de Tecnologia Educacional - ProInfo, visa criar e socializar novas formas de utilização das tecnologias digitais nas escolas públicas 
brasileiras, para ampliar o processo de inclusão digital escolar e promover o uso pedagógico das Tecnologias de Informação e Comunicação" [SEED/MEC, 2009, p.01].

A pesquisa em questão tem como temática a implementação do programa Um Computador por Aluno - UCA Total, no contexto das políticas públicas contemporâneas de inclusão digital na educação básica, no município de São João da Ponta - SJP, no estado do Pará. Problematizando em que medida o projeto UCA Total, nesse município, promove a inclusão sócio digital preconizada em seus objetivos.

O que se desdobra em questões: o que, de fato, essa inclusão digital preconizada pelo UCA proporcionou aos diversos atores envolvidos, sobretudo os estudantes, em São João da Ponta? Como eles próprios (re) significam o UCA e seus resultados? Desse objetivo central e das perguntas decorrentes, especificamente, objetiva: a) analisar qual abordagem de inclusão digital esta presente nos marcos legais do programa UCA; b) verificar a existência de infraestrutura física, de conexão de acesso e a disponibilidade de laptop, na escola e na comunidade de SJP, para inclusão digital dos participantes; c) compreender como estudantes e famílias (re) significam o UCA Total e seus resultados no município; e, por fim, d) analisar em que medida o UCA Total leva a inclusão sóciodigital dos participantes do projeto em SJP.

Para tanto, tomamos como categoria analítica norteadora deste trabalho a noção de inclusão sócio-digital, considerando que esta não se limita ao uso e manuseio do artefato tecnológico, possuindo a perspectiva de ir além, na medida em que possibilita o indivíduo compreender melhor a sua realidade e, a partir deste entendimento, exercer a cidadania, uma abordagem pautada na idéia da inclusão social por meio da inclusão digital. Para tal empreitada realizamos, neste estudo, uma pesquisa de cunho etnográfico [Pfaff, 2010].

O trabalho está dividido em 7 tópicos. Iniciamos com a introdução, em seguida tem-se uma discussão teórica sobre inclusão digital e a inclusão sócio digital, no tópico seguinte fez-se uma apresentação geral do o projeto UCA, no quarto apresentamos a metodologia, para posteriormente fazer a análise e discussão dos resultados, no sexto tópico apresento as considerações finais e por fim as referencias.

\section{Discussão teórica}

\subsection{Entre a inclusão digital e a inclusão sócio digital}

O Projeto UCA possui entre seus objetivos diminuir a exclusão digital das populações favorecidas. Neste sentido, distribuir os laptops UCA aos alunos em São João da Ponta - PA e possibilitar o acesso à internet já seriam fatores suficientes para analisar a inclusão digital do projeto, mas como analisar as implicações sócio-digitais do UCA em São João da Ponta? Para tal análise, consideramos além do uso do computar e acesso a internet [Libâneo et al, 2011; Néri, 2003; Silveira, 2001] outros fatores, como aprendizagem para uso do computador e da internet de modo socialmente válido [Warschauer, 2006]. Assim, considerando Warschauer [2006], discutimos inclusão digital, tomando por referência a abordagem de inclusão sócio-digital, como norteadora desta pesquisa neste município no estado do Pará.

A abordagem de inclusão sócio-digital é aqui entendida como muito mais que fornecer o acesso ao computador e conexões à internet [Silveira, 2001], visão clássica de inclusão digital, é mais que isso é "complexo conjunto de fatores, abrangendo recursos e relacionamentos físicos, digitais, humanos e sociais" [Warschauer, 2006, p. 
21] de modo que as pessoas utilizem à tecnologia de forma satisfatória e sejam verdadeiramente incluídas, pois "a capacidade de acessar, adaptar e criar novo conhecimento por meio do uso da nova tecnologia de informação e comunicação é decisivo para a inclusão social na época atual" [Warschauer, 2006, p.25].

Sobre a inclusão sócio-digital e o projeto UCA verifica - se que este programa em sua concepção contempla não apenas o acesso ao Laptop UCA e a internet, tendo em seus objetivos e finalidades a união de aspectos educacionais, sociais e tecnológicos [Valente \& Martins, 2011] como princípios orientadores formulados a partir de uma proposta com concepção pedagógica inovadora.

Neste artigo, partimos do pressuposto de que as políticas de inclusão digital não deve se dar de qualquer maneira, com "equipamentos sucatados, cursos precários, ambientes improvisados, treinamentos encurtados, programas baratos" [Demo, 2011, p.38], de forma desorganizada e sem recursos, apenas para torná-los incluídos, fazendo parte do sistema, da nova conjuntura mundial. Onde os pobres estariam dentro da inclusão digital "mas lá na margem, quase caindo fora do sistema" [Demo, 2011, p.36]. E entre os fatores que contribuem para a exclusão sócio-digital, estariam os níveis de instrução e renda dos indivíduos [Cysne et al, 2011].

Nesse sentido, Warschauer [Warschauer, 2006], coloca que a posse de um equipamento e a internet faz parte do acesso as Tecnologias de Informação e Comunicação - TICs, mas não é um acesso completo, pois considera ser necessário que o usuário desenvolva "habilidades e entendimentos para utilizar o computador e a internet de modo socialmente valido" [Warschauer, 2006, p.55], considerando anacrônico os tipos mais comuns de modelos de acesso às TICs em programas de inclusão digital baseados em equipamentos e conectividade, diz que estes são insuficientes para se pensar a inclusão social na era da informação, propondo um modelo mais plausível que seria baseado no letramento que considera "a capacidade pessoal do usuário fazer uso desse equipamento e dessa rede, envolvendo-se em práticas sociais significativas" [Warschauer, 2006, p.66]. É essa perspectiva que orienta a pesquisa etnográfica sobre o projeto UCA Total em São João da Ponta no estado do Pará.

\section{O Projeto UCA}

As políticas públicas, principalmente a partir do ano 2000, trouxeram em seu bojo uma visão alicerçada na concepção da informática na educação, como possibilidade de melhorar a educação e permitir a inclusão digital da população favorecida, promovendo a inclusão digital dos alunos. Assim, a concepção da informática em nosso país, a partir do século XXI, está alicerçada na idéia de inserir o Brasil na Sociedade da Informação [Takahashi, 2000], onde a educação seria um dos pilares para tal objetivo. É neste cenário de mudança de foco da informática educativa, abarcando a idéia de inclusão digital, que o governo brasileiro desenvolve políticas públicas como o programa UCA.

O projeto UCA surge em 2007 como uma política pública que procura introduzir o computador e o acesso à internet como ferramenta pedagógica em favor do aprendizado. A concepção do projeto surge no Fórum Econômico de Davos, na Suíça, em 2005, com a idéia de um laptop para cada criança. De acordo com o site do MEC/UCA [2013], o programa UCA possui o objetivo de "ser um projeto Educacional 
utilizando tecnologia, inclusão digital e adensamento da cadeia produtiva comercial no Brasil", apresentando fatores econômicos, sociais e educacionais em seu escopo.

O Governo Federal planejou o programa UCA - PROUCA, convertido em lei em 2010, em duas fases: fase 1 (Projeto Pré-piloto) e fase 2 (Projeto Piloto). A primeira fase iniciou em 2007, onde foram selecionadas cinco escolas, em cinco estados, como experimentos iniciais: em São Paulo-SP, Porto Alegre-RS, Palmas-TO, Piraí-RJ e Brasília-DF.

A segunda fase iniciou-se em Janeiro de 2010, as escolas participantes foram selecionadas pelas Secretarias de Educação dos Estados ou Municípios e também a União Nacional dos Dirigentes Municipais de Educação - UNDIME. Todos os Estados participantes indicaram suas escolas da Rede Estadual e Municipal. E, destas escolas, por iniciativa dos governos Federal, Estaduais e Municipais, alguns municípios tiveram todas as suas escolas atendidas pelo projeto, fazendo parte do projeto UCA Total. Os municípios selecionados foram: Barra dos Coqueiros/SE; Caetés/PE; Santa Cecília do Pavão/PR; São João da Ponta/PA; Terenos/MS e Tiradentes/MG.

No estado do Pará, de forma a viabilizar a implementação do projeto UCA nos municípios contemplados, esses passaram a receber o sinal do programa de inclusão digital Navega Pará, um programa de inclusão digital do Governo do Estado, lançado em 2007, que tem a missão de levar a internet e cidadania digital a populações desfavorecidas e promover a integração territorial.

\section{Metodologia}

De forma a atingir os objetivos propostos, realizamos uma pesquisa de campo de cunho etnográfico, com o intuito de realizar uma descrição narrativa do projeto UCA em São João da Ponta, considerando o contexto, a cultura e os significados a ele atribuídos por diferentes sujeitos nesta localidade.

A pesquisa etnográfica ocorreu no período de agosto de 2012 a maio de 2013. Onde foram feitas fotografias, observações, anotações em diário de campo sobre a realidade local e das questões da pesquisa, também foram realizadas conversas e entrevistas com ex-estudantes, estudantes, gestores e famílias nos vários espaços do município. As conversas foram gravadas e anotadas num diário de campo, assim como as entrevistas que foram transcritas e analisadas. De forma a mapear as escolas do UCA Total e as localidades onde estão inseridas, inicialmente, visitamos todas as escolas do município de SJP. A escola escolhida para fazer-mos uma abordagem mais detalhada com estudantes e suas famílias por meio de entrevistas qualitativas foi a estadual de ensino médio Antônia Rosa.

Em SJP, são 14 escolas atendidas pelo projeto em SJP, 13 municipais e 01 estadual. Deste total, 07 escolas ficam na área urbana, 05 na sede do município tais como; E.E.E.M Antonia Rosa; E.M.E.F Antonia Rosa; E.M.E.I 15 de Agosto; E.M.E.F Feliciano Rodrigues; E.M.E.F Feliciano Rodrigues; E.M.E.I Tia Biá e 02 escolas em vilas próximas a sede como a E.M.E.F Clarinda Rodrigues em Vila Monte Alegre e a escola E.M.E.F Açu em Vila Açu.

Outras 07 escolas ficam na área rural, são elas: E.M.E.F Cipriano Chagas em Vila Bonfím; E.M.E.F Rosa Almeida em Vila Coqueiro; E.M.E.F Raul Lagoia; E.M.E.F Brígido Coelho em Vila Guarajuba; E.M.E.F Romualdo Almeida; E.M.E.F Guarumã Pucu em Vila Santa Clara e E.M.E.F Teodoro Gurjão em Vila Porto Grande. 
Na tabela 01, abaixo, apresentamos os sujeitos da pesquisa, do município de SJP, encontrados nos diversos espaços. São ex-estudantes, estudantes e famílias participantes do estudo, encontrados em vários espaços do município estudado e os estudantes e famílias entrevistadas, expondo, ocupação, série, principal atividade com o UCA e o local de residência.

Tabela 01: Estudantes e Ex-estudantes e famílias em SJP

\begin{tabular}{|c|c|c|c|}
\hline Sujeitos & Ocupação & $\begin{array}{l}\text { Principal atividade } \\
\text { com computador }\end{array}$ & Local da Residência \\
\hline Estudante YO & $\begin{array}{l}\text { estudante } \\
\text { ensino médio }\end{array}$ & $2^{2}$ rede social & Sede de SJP \\
\hline $\begin{array}{l}\text { Ex - estudante } \\
R L\end{array}$ & $\begin{array}{l}\text { ex-estudante } \\
\text { ensino médio }\end{array}$ & $\begin{array}{l}\text { rede social } \\
\text { pesquisa }\end{array}$ & Vila Açú \\
\hline Ex -estudante CN & $\begin{array}{l}\text { ex-estudante } \\
\text { ensino médio }\end{array}$ & $\begin{array}{l}\text { dorede social } \\
\text { pesquisa }\end{array}$ & Vila Açú \\
\hline $\begin{array}{l}\text { Estudante }{ }^{\star} \text { EN/ } \\
\text { Família EM }^{\star \star}\end{array}$ & $\begin{array}{l}\text { estudante } \\
\text { ensino médio }\end{array}$ & $\begin{array}{l}30 \text { rede social } \\
\text { pesquisa }\end{array}$ & Sede de SJP \\
\hline Estudante RO & $\begin{array}{l}\text { estudante } \\
\text { ensino médio }\end{array}$ & 2 rede social & Vila Guarajuba \\
\hline Ex -estudante JV & $\begin{array}{l}\text { ex-estudante } \\
\text { ensino médio }\end{array}$ & trabalho & Vila Monte Alegre \\
\hline $\begin{array}{l}\text { Estudante* CS/ } \\
\text { Família } \text { CS }^{\star *}\end{array}$ & $\begin{array}{l}\text { estudante } \\
\text { ensino médio }\end{array}$ & $2^{\mathrm{o}}$ rede social & esede de SJP \\
\hline $\begin{array}{l}\text { Estudante }^{\star} \\
\text { Família NS }^{\star \star}\end{array}$ & $\begin{array}{l}\text { estudante } \\
\text { ensino médio }\end{array}$ & 30 rede social & Sede de SJP \\
\hline $\begin{array}{l}\text { Estudante* } \\
\text { Família JR }^{\star \star}\end{array}$ & $\begin{array}{l}\text { estudante } \\
\text { ensino médio }\end{array}$ & $\begin{array}{l}3 \text { orede social } \\
\text { pesquisa }\end{array}$ & Sede de SJP \\
\hline
\end{tabular}

As conversas com os estudantes e ex-estudantes foram realizadas sempre que se encontrava aluno usando o UCA pela cidade e aconteceram em diversos espaços. A pesquisa apontou que os principais locais de uso do UCA eram: praça da sede de SJP; próximo as escolas; próximo a sede de SJP e nas residências dos estudantes. Esses locais de usos do UCA, davam-se principalmente por serem locais de bom acesso a internet. Nos tópicos seguintes, apresento os resultados e as análises da pesquisa realizada no município pesquisado.

\section{Análise e discussão dos resultados}

\subsection{As escolas do Projeto UCA do em São João da Ponta}

Em SJP, as escolas públicas, municipais e estaduais, reúnem em torno de 1.223 alunos e cerca de 80 professores. Para conhecer os loci do UCA Total em SJP, realizamos visitas a todas as escolas do município, com o objetivo de conhecer todas as vilas e escolas participantes do UCA; observar a inclusão digital proporcionada pelo projeto; verificar a infra-estrutura física e de conexão lógica dessas escolas e também conversar com os gestores das escolas visitadas sobre o programa UCA Total. 
As visitas mostraram que em nenhuma escola foi realizada a adequação de espaço físico, sendo que apenas foram colocadas tomadas nas salas de aula. Muitas escolas não receberam carteiras específicas para o projeto. Porém, algumas anteriormente já possuíam escrivaninhas e apenas uma escola, a estadual Antônia Rosa, recebeu armário específico de carregar os laptops do programa em abril de 2013, mas que não estava funcionando devido à diferença de voltagem do armário e da rede elétrica da escola. Todas as escolas visitadas tinham instalação de rede lógica (mesmo as escolas de Educação Infantil) e das 14 escolas visitadas, 06 possuíam conexão a internet, sendo 05 da zona urbana e apenas 01 da zona rural. Os gestores também informaram que no início do projeto todos os alunos a partir da terceira série receberam o UCA.

$\mathrm{Na}$ área urbana, as escolas da sede possuem conexão a internet disponibilizada pelo programa do governo estadual Navega Pará, embora alguns gestores relatem que "o sinal era bom dava pra fazer muita coisa, mas se todo mundo usa o sinal começa a cair e os professores reclamam muito desse problema". Disseram também que eles usam o UCA, mas que "dá muito problema, pois imagina uma sala com 30 alunos todos usando o UCA? O sinal fica ruim, a energia fica fraca e cai mas é assim mesmo, tem que tentar."

$\mathrm{Na}$ zona rural, apenas 01 escola possui conexão a internet - feita pelo GESAC, porém, de acordo com o gestor, o sinal é de baixa qualidade, apresentando frequentemente problemas técnicos que deixam a escola sem internet por um longo período de tempo, o que dificulta o desenvolvimento de ações de uso da internet no UCA pelos professores e alunos em sala de aula, como exposto na fala de um diretor: "a internet era um problema para o trabalho com o UCA, pois era muito ruim, mas eles faziam o possível tentavam pelo menos uma vez, dia de quarta ou quinta, mas era muito difícil".

\subsection{Os processos de inclusão digital e o UCA}

No sentido observar processos de inclusão digital experienciados pelo UCA Total em SJP, analisamos as informações coletadas no campo em três dimensões que são: 1) aprendizagens pelo UCA; 2) sociabilidades em rede; 3) mudanças econômicas, sociais e educacionais propiciadas pelo projeto em São João da Ponta.

\subsubsection{Aprendizagens pelo UCA.}

Sobre as Aprendizagens pelo UCA, verificamos os diferentes tipos de aprendizagens propiciados pelo UCA em diferentes espaços, como escola - praça casa, com estudantes e ex- estudantes, observando como este aprendeu, se sozinho, com o professor ou em grupo. E o que, de fato, aprendeu. E se ocorreram, segundo Warschauer [2006], comunidades práticas "que são rede de pessoas dedicadas a atividades similares, aprendendo umas com as outras no processo" (p.166).

Verificamos que na escola os alunos aprenderam com o professor, com o colega e com o grupo. Na praça, sem dúvida foi um dos locais mais ricos em aprendizagens na sede de SJP. Em casa, o aluno conseguiu difundir os conhecimentos aprendidos na escola e na praça aos pais e familiares, sendo o principal elemento de inclusão digital da comunidade extra-escolar.

Na praça a aprendizagem se deu na relação com colegas, apresentando indícios de formação de comunidades práticas, havendo também neste espaço uma 
potencialização de letramentos. Em casa, por conta da mobilidade do UCA, permitiu a "expansão dos espaços" de uso do laptop atingindo as famílias [Brasil, 2007, p.14], expansão esta que promoveu uma nova cultura tecnológica na maioria das famílias entrevistadas com o reconhecimento do potencial do UCA para aprendizagens dos alunos.

A praça é lembrada como o principal local de acesso à internet no início do programa, como relatado: "lá na praça ficava cheio de gente, o sinal ficava meio ruim é verdade, mas era muito legal, a gente ficava até tarde, tinha pai buscando filho e tudo mais, égua era muito legal ficar lá no computador conversando com o pessoal da escola" (Estudante EN). A partir das entrevistas observou-se que a praça era o local de maior interação e trocas de experiências para além de uso meramente instrumental do UCA, ou seja, neste espaço há indícios de desenvolvimento de comunidades práticas [Warschauer, 2006].

\subsubsection{Sociabilidades em rede}

Em relação às sociabilidades, verificamos com os participantes da pesquisa a presença de sociabilidades on-line, propiciadas pelo UCA e a internet, que poderiam emergir do campo de pesquisa, observando também questões como isolamento social do indivíduo, ruptura da comunicação social e da vida familiar [Castells, 2003], entre outros pontos. Essas novas sociabilidades ocorreriam na relação dos sujeitos no ciberespaço por meio da internet, seja usando o e-mail, facebook, twiter, chats, MSN, entre outros dispositivos, originando novos padrões seletivos e de interação.

Observamos que todos os estudantes entrevistados participam de alguma rede social, a principal é o Facebook seguido pelo Twitter. As famílias também desenvolveram novas sociabilidades: "eu uso o Facebook é mais moderno (risos) e cada vez mais modernizado, eu falo com gente de todo lugar de Belém e até de fora..." (FAMÍLIA JR). Os entrevistados colocaram que por meio do laptop UCA fizeram novos amigos: "Conheci umas pessoas pelos chat's, de algumas cidades" (ESTUDANTE CS). O estudante NS diz: "Fiz novos, e mantive os daqui mesmo".

Os efeitos na construção de sociabilidades para os participantes foram à diminuição das distâncias geográficas, construção de laços na rede, manutenção de laços on line e of line, além da percepção de novas formas de comunicação além das conhecidas por eles, como telefone.

\subsubsection{As mudanças econômicas, sociais e educacionais propiciadas pelo projeto em São João da Ponta}

Analisamos as mudanças proporcionadas pelo UCA com os estudantes, exestudantes, famílias e gestores, a partir dos aspectos educacionais, sociais e econômicos do projeto UCA, considerando para tanto os objetivos, finalidades e concepções do programa [Valente \& Martins, 2011].

As mudanças econômicas foram consideradas a partir do uso UCA para melhorar a renda dos participantes da pesquisa e da comunidade do município. Para as mudanças sociais verificaremos indícios de transformações na realidade sociocultural da comunidade de SJP e também mudanças de comportamento, atitudes e valores dos envolvidos. Por fim, as mudanças educacionais serão consideradas, bem como as expectativas e se houve modificações, transformações nos espaços e tempos escolares, e na prática escolar dos professores pelos sujeitos da pesquisa. 
São João da Ponta é um município pobre do estado do Pará, e de acordo com o IBGE/2009, vive principalmente de repasses da União. Da primeira vez que fomos ao município, em 2010 e depois em 2012 e 2013, não vimos grandes mudanças na estrutura econômica na sede do município, que apresentava praticamente as mesmas lojas e comércios do período anterior. A pesquisa mostrou que, a partir do projeto UCA, alguns participantes conseguiram desenvolver soluções de problemas no seu trabalho por meio do uso da tecnologia: "A minha mãe, ela é responsável por uma loja, aí depois que aprendeu a usar o UCA, eu ensinei também, mas ela fez curso lá na escola assistindo aula comigo, ela informatizou a loja pra não perder cliente, acho que se não fosse o projeto não seria assim, daí depois que tiraram o UCA da gente, minha mãe guardou durante vários meses dinheiro pra comprar um laptop pra casa" (ESTUDANTE NS).

O projeto UCA possibilitou aos estudantes e suas famílias novas formas de lidar com o mundo real e abrir portas para novos sonhos, novas possibilidades, como exposto "Modificou, depois do UCA a gente consegue ficar aqui mas ir em outros locais, eu tô estudando mas quero ir pra Belém, fazer uma universidade, não quero ter a vida igual a da mamãe..." (ESTUDANTE JR). Outro aluno diz: "Demais! SJP ficou, digamos assim, mais 'digital', mais interado dos assuntos..." (ESTUDANTE CS). Assim, o UCA e a internet possibilitaram aos estudantes o acesso a informação e a imersão na sociedade do conhecimento.

Quanto às mudanças na escola e na prática escolar, por conta do UCA, alguns estudantes expuseram que a principal mudança na prática escolar foi a troca dos livros didáticos ou jornais pelo laptop como principal ferramenta para pesquisa escolar como podemos ver nas falas a seguir: "Nada não a escola ficou na mesma, só os professores que mudaram pois antes a gente usava livros pra pesquisar os trabalhos da escola, aí depois do projeto UCA agente passou a usar o laptop" (ESTUDANTE JR). Sobre isso concordarmos com Lavinas (2012), quando diz que o "uso pedagógico das TICs em sala de aula é ainda tímido frete as descobertas que crianças e jovens fazem fora dos muros escolares" (p. 29).

Podemos dizer que os objetivos educacionais foram atingidos em parte onde a educação formal não foi potencialmente beneficiada em SJP; porém, a educação informal foi de certa forma bem sucedida. Notamos que o uso do UCA pelos participantes, nos vários espaços além-escola, permitiu o desenvolvimento de outras habilidades além do mero uso técnico do computador e internet. Observamos também que a população da sede foi potencialmente incluída no mundo digital desenvolvendo hábitos, atitudes e valores em relação ao computador e internet.

\section{3 projeto UCA e a inclusão sócio digital em São João da Ponta}

Tomando os indicadores de Warschauer [2006], acerca da Inclusão Sócio Digital - ISD, temos o seguinte situação, na tabela 02, em SJP:

Tabela 02: Indicadores de ISD em SJP.

\begin{tabular}{|l|l|l|l|}
\hline $\begin{array}{l}\text { Indicadores de } \\
\text { inclusão } \\
\text { digital }\end{array}$ & \multicolumn{2}{|l|}{ Área urbana de SJP } & \multirow{2}{*}{ Área Rural SJP } \\
\cline { 2 - 3 } & Sede & Vilas & sim \\
\hline Infraestrutura lógica* & $\operatorname{sim}$ & $\operatorname{sim}$ & não \\
\hline Conectividade & $\operatorname{sim}$ & $\mathrm{nt}^{* *}$ & \multicolumn{2}{|l|}{} \\
\hline
\end{tabular}




\begin{tabular}{|l|l|l|l|}
\hline Letramento & $\operatorname{sim}$ & não & não \\
\hline $\begin{array}{l}\text { Indícios de Sistemas } \\
\text { Sociais e Comunidade } \\
\text { Prática }\end{array}$ & $\operatorname{sim}$ & não & não \\
\hline
\end{tabular}

Fonte: Elaborado pela autora

*Não confundir com infraestrutura física da escola.

**NT - Nem Todas.

Desta forma, podemos considerar que as escolas rurais e a grande maioria das vilas urbanas de SJP não tiveram acesso nem mesmo a inclusão digital baseada no acesso ao computador e internet. As escolas e a comunidade da sede foram potencialmente beneficiadas pelo UCA, onde percebemos indícios de letramento digital pelos participantes e também o desenvolvimento de comunidades práticas [Warschauer, 2006]. Porém, o projeto não impregnou na escola sendo potencialmente absolvido pela comunidade.

Em síntese, o UCA Total é um projeto educacional com objetivos econômicos, sociais e educacionais tendo a escola como lócus principal de atuação. Este em SJP, pode ter atingido objetivos econômicos e sociais, mas não os educacionais dentro do espaço escolar com a perspectiva de melhoria da qualidade da educação com a imersão de estudantes e professores numa cultura digital. Entretanto, possibilitou outras aprendizagens nos vários espaços da sede de SJP aos estudantes, ex-estudantes envolvidos e seus familiares.

Assim, considerando a análise das dimensões que constroem os processos de inclusão digital do projeto em SJP, pelo UCA (as aprendizagens, sociabilidades e mudanças na localidade), podemos concluir que no espaço além-escola, na comunidade da sede deste município, há indícios de uma tímida mas presente inclusão sócio-digital dos variados sujeitos envolvidos.

\section{Considerações Finais}

O projeto UCA em SJP não conseguiu impregnar na escola, lócus primeiro de sua atuação, entre os fatores que podem ter colaborado para tal resultado na escola podemos citar a instalação atropelada do projeto no município; a questão da formação dos professores para uso efetivo das TICs e uma efetiva infra-estrutura física nas escolas beneficiadas. Porém o projeto se desenvolveu bem fora do espaço escolar onde crianças, jovens, as famílias de SJP, foram fortemente impactadas com a inclusão digital proporcionada pelo UCA.

O Projeto, no município pesquisado, possibilitou a inserção de parte da população de SJP na era da informação, mas essa inserção, não correspondeu a mudanças significativas nas condições de estrutura física e de pessoal da educação formal, saúde, habitação, saneamento da população em geral. $O$ posto de saúde continuou sem médico, a maioria das ruas continuou sem saneamento e a escola continuou sem biblioteca e com as mesmas práticas educacionais de antes do programa.

Observamos em São João da Ponta que o projeto UCA, inicialmente inserido com objetivos educacionais, não vingou na escola, local primeiro de atuação, e foi para a comunidade, que estabeleceu um conceito de inclusão digital para as práticas e usos na vida cotidiana, possibilitando não só conhecer outras realidades pela internet, mas também buscar na rede informações realmente válidas em suas vidas, como: emprego, 
estudos e cursos com indícios de uma inclusão sócio digital aos participantes. Em São João da Ponta, o projeto UCA precisa ser repensado, principalmente no âmbito da escola com a interlocução de seus atores numa real perspectiva de se inserir o projeto neste espaço.

\section{Referências}

Brasil. Princípios orientadores para o uso pedagógico do laptop na educação escolar. Brasília: MEC/SEED. (2007).

Castells, M. A Galáxia da Internet: Reflexões sobre a Internet, os negócios e a sociedade. Rio de Janeiro: Jorge Zahar Editor, 2003.

Cysne et al. O desafio da exclusão digital: uma análise multivariada com base na Pnad 2005. In: Revista Ibict: inclusão social. Vol. 2, número 2, 2007. Disponível em: $<$ http://www.ibict.br/revistainclusaosocial>. Acesso em: 25 set. 2011.

Demo, P. Inclusão digital - cada vez mais no centro da inclusão social. In: Revista Ibict: inclusão social. Vol. 1, número 1, 2005. Disponível em: $<$ http://www.ibict.br/revista inclusaosocial/viewarticle.php?id=4\&layout=html $>$. Acesso em: 25 set. 2011.

Lavinas, L \& Aline, V. O Programa UCA - TOTAL: desafios do modelo brasileiro de inclusão digital pela escola. 36 encontro anual da ANPOCS, GT29 - Políticas Públicas, 2012. Águas de Lindóia - SP.

Libâneo et al. Educação Escolar: políticas, estrutura e organização. 10 $0^{\text {a }}$ Edição. São Paulo: Cortez, 2011.

MEC/UCA - Ministério da Educação. Disponível em: < http://www.uca.gov.br/ institucional/index.jsp. 13/08/2013>.

Neri, M. C (coord). Mapa da exclusão digital. Rio de Janeiro: FGV/IBRE, CPS, 2003.

Pfaff, N. Grupos de discussão: aportes teóricos e metodológicos. In: Weller, W.; Pfaff, N (Org.) Metodologia da Pesquisa qualitativa em Educação: Teoria e Prática. Petrópolis, RJ: Vozes, 2010. p. 54-66.

SEED/MEC. Projeto Um Computador por Aluno: Formação Brasil. Vol. 1. Brasília: Secretaria de Educação a Distância, 2009.

Silveira, S. A. Exclusão Digital: a miséria na era da informação. São Paulo: Fundação Perseu Abramo, 2001.

Sorj, B. brasil@povo.com: a luta contra a desigualdade na Sociedade da Informação. Rio de Janeiro: Jorge Zahar Ed.; Brasília,/DF: Unesco, 2003.

Takahashi, T. (Org) Sociedade da Informação no Brasil. Livro Verde. Brasília: MCT, 2000.

Valente,J.A \& Martins, M.C. O Programa Um Computador por Aluno e a Formação de Professores das Escolas Vinculadas à Unicamp. In: Revista Geminis, ano 2, número 1, p.116-136. (2011).

Warschauer, M. Tecnologia e Inclusão social: a exclusão digital em debate. $1^{\text {a }}$ São Paulo: Senac, 2006. 319 p. 